\title{
¿Gozan de validez universal los sistemas educativos?
}

Por sistema educativo entendemos el conjunto de principios teóricos, organizativos y prácticos, que fundamentan el concepto de educación y su realización en un marco cultural determinado. Los sistemas educativos son plurales, porque es más oportuno hablar de ciencias de la educación que de "ciencia" única, de "pedagogías" más que de una sola pedagogía. Si los sistemas educativos tuvieran validez universal, resultaria imposible la pluralidad de teorias, ya que sólo una de ellas gozaría de aceptación, consistencia y perdurabilidad en el tiempo y en el espacio.

La cuestión aquí cuestionada es antigua, dentro de la corta vida histórica de las ciencias de la educación, pues fue G. Dilthey. quien la planteó abiertamente hace ya bastantes años ${ }^{1}$; es decir, los relativismos filosóficos se opusieron a la postura más común hasta principios de siglo, que mantenía la absolutez y la inmutabilidad como prerrogativas de formulaciones filosóficas, tal y como insinuó el aristotelismo y difundió más tarde, en occidente, la escolástica.

La opinión más aceptada es la de aquellos que piensan en la necesidad de fundamentar la ciencia de la educación en otros saberes, principalmente en saberes filosóficos, por lo cual la validez universal de los sistemas pedagógicos correrá las mismas vicisitudes que la filosofía que los sustenta.

1. Hipótesis acerca de la validez universal de los sistemas educativos

La primera hipótesis es la afirmativa, o sea, la de quienes aseguran que un sistema educativo puede tener vigencia temporal y espacial de signo universal. La totalidad de los defensores de esta hipótesis pertenecen a movimientos teóricos educativos de signo

1. G. DILTHEY, Fundamentos de un sistema de Pedagogía. Buenos Aires, 1944. 
aristotélico o a corrientes culturalistas universalistas. En los Estados Unidos de América florecen, en la actualidad, movimientos de esta índole, que encuentran raíces en la filosofía helénica, en Santo Tomás o en las modernas doctrinas del francés Jacques Maritain, profesor extraordinario en la Universidad de Princeton ${ }^{2}$.

Una de las teorias educativas, adictas a esta primera hipótesis, y de fuerte raigambre principalmente entre los católicos norteamericanos es el perennialismo, el cual se apoya en principios tales como: "En todas las partes los hombres son básicamente iguales, por ellos la educación debe ser igual para todo el mundo"; "la labor de la educación consiste en adaptar los hombres a la verdad, que es eterna, más que al mundo contemporáneo, que no le es"; "Hay que enseñar al niño ciertas materias básicas que le familiarizarán con la permanencia del mundo"; "la educación debe familiarizar al alumno con los intereses generales de la humanidad a través del estudio de las grandes obras de la literatura, filosofía, historia y ciencias en las que han sido expresados". Esta tendencia ha sido reprensentada por $R$. M. Hutchins, Presidente de la Universidad de Chicago, y $M$. J. Adler, de la Universidad de Columbia; y por el idealismo de W. T. Harris y H. H. Horne ${ }^{3}$.

El universalismo culturalista insiste en la consistencia de la naturaleza humana, la objetividad y la fijeza de las pautas morales, además de aceptar un esquema de necesidades observables en todas las culturas. La cultura tiene características comunes: los límites a la violencia, el sentimiento de lealtad, ciertos modos de ganarse la vida, los sistemas familiares, el código moral, la concepción del hombre, el lenguaje y la organización social; pero a pesar de estas constantes culturales se admiten el cambio social y las modalidades peculiares de cada época y lugar ${ }^{4}$. Por la educación, según esta concepción culturalista, el hombre perfecciona el último reducto de su hominidad, que es la razón. El universalismo cultural ha tenido defensores tan conspicuos como C. Kluckhohn, G. P. Murdock, R. Linton... ${ }^{5}$.

2. J. MARITAIN, La educación en este momento crucial. Buenos Aires 1965.

3. Ch. WEBER, Basic Philosophies of Education (New York 1960) 124-139.

4. R. REDFIELD, "Anthropology's Contribution to the Understanding of man": Anthropological Quartely 32 (1959) 13-18.

5. C. KLUCKHOHN, "Universal Categories of Culturs": Anthropology Today (Chicago 1953) 520-521; G. J. MURDOCK, "The common Denominator of Cultures": R. LINTON (Ed.), The Science of Man in the World Crisis (New York 1945) 134; G. F. KNELLER, Introducción a la antropología educacional (Buenos Aires 1974) 55-59. 
La segunda hipótesis es la negativa, es decir, la proclive al relativismo culturalista y educacional. Es lógico que sea el relativismo filosófico, dado el paralelismo observable entre estos dos fenómenos ideológicos, quien garantice el relativismo educacional. En efecto, G. Dilthey, con sus perspectivismo histórico y con su relativismo vitalista, es uno de los representantes más genuínos del relativismo educacional, con repercusiones en nuestra patria a través de ortega y Gasset. En general, podemos decir que las denominadas pedagogias no-directivas están más próximas a esta segunda hipótesis que a la primera, con la que sintonizan más las pedagogías directivas y tradicionales.

El relativismo culturalista es más frecuente que el universalismo de los Estados Unidos, donde $F$. Boas, $R$. Benedict y $A$. L. Kroeber han sido los abanderados de la idea de que cada cultura es irrepetible y debe ser analizada con sus propias categorias. En el fondo del relativismo cultural late la convicción de que la naturaleza humana es relativa al tiempo y al lugar, es decir, se propugna un relativismo antropológico y una relativismo moral, en la persuasión de que los valores éticos son sólo válidos para la cultura que los crea y los acepta. El relativismo educacional sostiene que ninguna forma de educación es universalmente válida ${ }^{6}$. El sistema norteamericano que mejor encarna el relativismo educacional es el progresismo, fruto del experimentalismo instrumentalista de J. Dewey. En la misma Norteamérica, e incluso en posiciones educativas afines, el progresismo ha sido inculpado de un relativismo exagerado y estéril; tal es la acusación formulada por Th. Brameld, principal promotor del reconstruccionismo educativo.

La tercera hipótesis es intermedia, pues acepta, por un lado, la constancia, la validez universal y la inmutabilidad de los primeros principios de los sistemas educativos, en cuanto se fundan sobre la naturaleza, entendida como fuente de modelos universales; modificables únicamente por el carácter evolutivo del ser humano; y, por otro, la mutabilidad, fluidez, inconsistencia y relativismo de las culturas en medio de las cuales se han elaborado los sistemas educativos. El binomio naturaleza-cultura es la clave para conjugar lo mutable y lo inmutable, lo universal y lo particular, lo consistente y lo cambiante, porque no se predican estas antinomias bajo el mismo aspecto y formalidad, aplicadas a la misma realidad, sino que se

6. E. DURKHEIM, Education and Society (New York 1956) 64; R. BENEDICT, "Transmiting our democratic Heritage in the Schools": B. E. MERCERE. R. CARR (Eds.), Education and the social Order (New York 1957) 214. 
dicen de dimensiones diversas intervinientes en el proceso educativo individual y social. Esta tercera hipótesis es la que nosotros presentamos.

\section{Fundamentación de la hipótesis intermedia}

2.1. Fundamentación antropológica. La antropogénesis, tanto filogenética como ontogenéticamente, presupone la identidad diacrónica de la especie y de la persona, por más que se comprueben alteraciones y mutaciones notables e importantes. Las mutaciones filogenéticas y las crisis personales avalan la identidad de la especie y del individuo. Más aún, en el hombre lo definitivo y acabado está raciicado principalmente en los estratos biológicos; en tanto que lo cambiante radica en la apertura característica del ser humano, apertura que explica la educabilidad. Es cierto que en las culturas más desarrollados se registran una madurez cerebral y un grado de evolución que no existen en las culturas más primitivas; pero aun con unas configuraciones neurológicas similares, la cultura y la sociedad condicionan los sistemas educativos.

Rechazamos el relativismo antropológico y moral, pero abogamos por el cambio, dentro de la identidad diacrónica y sincrónica del hombre; por idénticas razones, no podemos estar plenamente de acuerdo con fixismos, absolutismos y universalismo válidos temporal y espacialmente. Los sistemas educativos se han ideado para una coyuntura concreta, estimulados por esquemas políticos, económicos, axiológicos y filosóficos de un determinado momento histórico, en el que el ideal del hombre ha corrido paralelo con los planteamientos generales de aquel contexto.

No ha habido un tipo único de hombre, porque aún las dimensiones biológicas han variado según las razas, las condiciones ecológicas, los hábitos dietéticos... Pero aun prescindiendo de estás variaciones constitucionales, se constata un cambio en el patrón modélico cultural del hombre. Así, por ejemplo, la historia nos ofrece el hombre mágico-mítico de las culturas orientales antiguas, el hombre sereno y equilibrado por la razón en el esplendor del pueblo griego, el caballero medieval entusiasmado por las armas y el honor, el gentilhombre del renacimiento amigo de las relaciones atildadas y exquisitas, el hombre ilustrado del racionalismo europeo, el hombre romántico ansioso de evasiones en las épocas históricas más propicias a lo fabuloso, el hombre tecnificado y disperso de la era industrial, el hombre desalienado de la sociedad postindustrial... Lógicamente, los sistemas educativos, por su misma in- 
tencionalidad y teleologismo, se han fijado una meta distinta; de acuerdo con la imagen del hombre, de la que han partido. No obstante en todas estas variaciones hay un sustrato común, que justifica la defensa de ciertos niveles de invariabilidad. La educación no puede volver la espalda a estas realidades, sino que ha de contar con ellas. De aquí que haya propiciado experiencias nuevas, reformas y cambios para responder al desafio constante que la antropología le ha hecho y le continuará haciendo. $Y$ esto no es relativismo, sino evidencia y vida.

La antropologia psicológica sabe que el proceso de aprendizaje, tan emparentado con lo educativo, se produce en medio de circunstancias ambientales estimuladoras de respuestas; lo cual no significa la aceptación de la criticable base antropológica del conductismo, cuando prescindió de las más tarde llamadas "variables intermedias" u hombre interior, contrapuesto a lo periférico de los sentidos, aptos para la medida y el control experimental. La personalización y socialización, componentes básicos del proceso educativo, suponen aprendizaje; y éste, medio ambiente. Las variaciones ambientales hacen cambiar a los sistemas educativos, si éstos han de adecuarse a la realidad y preparar para ella.

2.2. Fundamentación cultural. La educación está íntimamente vinculada a la transmisión y creación de cultura. La teoría superorgánica de $E$. Durkheim enseña que la conducta humana está determinada por la cultura, porque ésta controla a los individuos ${ }^{7}$; y reduce la educación a la mera transmisión cultural por parte de las generaciones jóvenes, para que éstas se adapten a sus patrones conductuales. La interpretación del sociólogo francés es una visión parcialista $\mathrm{y}$, por tanto, inaceptable del proceso educativo, que ha de desencadenar la productividad cultural del hombre, convertido así en agente de la cultura y no en su simple receptor. Tanto si se atiende a la transmisión cultural como a la productividad humana, la educación no se ha verificado siempre de la misma manera. En el primer caso, porque cada generación adulta ha configurado un estilo de vida, el cual pretende transmitir; en el segundo, porque a través de la educación promocionamos la productividad cultural y, en consecuencia, el cambio. La educación ha de responder a las exigencias socioculturales de un país, plurales siempre en la historia.

"La antropología cultural demuestra, pues, de modo feha-

7. L. A. WHITE, The Science of Culture: A Study of Man and Civilization (New York 1955) 345-346. 
ciente que educación y formación no deben entenderse... cual funciones autoconservadoras y autopropagadoras del proceso cultural... La investigación antropológica-cultural demuestra, por el contrario, el carácter histórico de las relaciones entre hombre y cultura. Cuando se parte del supuesto que las objetivaciones espirituales y el espíritu subjetivo están sometidos al cambio histórico, no hay por qué temer la desaparición de todas las vinculaciones".8.

El proceso de enculturación supone una interiorización de la cultura en que ha nacido el sujeto y en la que continúa inmerso; el de aculturación, la asimilación de la nueva cultura en la que voluntariamente se sitúa un inmigrante. Ambos fenómenos culturales son parte del proceso educativo. Si de la enculturación y aculturación nos remontamos a la creación de formas y pautas nuevas de conducta y a la modificación constante que el hombre opera en la naturaleza, tendremos la clave de la tercera hipótesis en la cuestionada validez universal de los sistemas educativos. Si el hombre es criatura y creador de cultura, no puede aceptarse la validez universal ${ }^{9}$.

La doctrina contemporánea sobre el cambio social, que hace hincapié en la identidad persistente y en la sucesión de diferencias temporales corrobora también esta tercera hipótesis intermedia ${ }^{10}$. Es sabido que las dos funciones sociales primarias de la educación son el control social y el cambio social; el control social dice referencia a lo permanente, a lo que la generación adulta quiere hacer pervivir en la generación joven; pero el cambio social significa el resultado de complejos factores sociales o la meta que se busca mediante la manipulación del proceso educativo ${ }^{11}$. Imposible ejercer influencia en el cambio e incluso plantearle mediante la educación, si se defendiera la validez universal de los sistemas educativos.

Merece tratamiento especial la basic personality structure, expresión acuñada por $A$. Kardiner bajo inspiración freudiana y aceptada por el grupo norteamericano de "Cultura y personalidad". Estas investigaciones han estudiado las relaciones existentes entre la personalidad modal de una sociedad $y$ las circunstancias socioculturales, las prácticas de asistencia y la educación. Las diversos sistemas educativos configuran una personalidad modal sellada por la

8. E. WEBER, Estilos de educación (Barcelona 1976) 102.

9. G. F. KNELLER, Introducción a la Antropología, 61-89.

10. R. A. NISBET, Introdución a la sociología (Barcelona 1975) 295-391.

11. J. C. AGULLA, Educación, sociedad y cambio social. Buenos Aires, 1973. 
cultura especifica. Ahora bien, la personalidad básica varía según los grupos; y, por tanto, es imposible hablar de un sistema universalmente válido capaz de engendrar una personalidad invariable, porque las sociedades, -que indudablemente varian- demandan cambio en la personalidad modalmente más repetida en su seno.

2.3. Fundamentación axiológica. En relación con la posible validez universal de los sistemas educativos la axiologia brinda dos opciones, a las que se han adherido, de una u otra forma, la mayoría de los teóricos sobre los valores; los valores son inmutables y absolutos para unos, en tanto que para otros son mutables y relativos. Idénticas direcciones siguen los valores educativos. Los partidarios de la mutabilidad niegan la validez universal de los sistemas educativos; y los partidarios de la inmutabilidad les conceden dicha prerrogativa. Los relativistas dirán que la escuela ha de capacitar para enjuiciar los valores de las culturas pretéritas y para jerarquizar, mediante la propia reflexión, la escala más en consonancia con el presente, la cual ha de ser corregida en las evoluciones futuras sociales. Los absolutistas enconmiendan a la escuela la tarea de inculcar en los educandos la auténtica escala de los valores, los cuales han de salvaguardarse con esmero a lo largo de toda la vida.

Ante todo, es preciso puntualizar qué entendemos por "valor". Las definiciones que de él se han dado son descriptivas y acumulan características una y otra vez reiteradas: el valor es un objeto ideal, es una realidad digna de aprecio, es un proceso epistemológico, es una pérdida de la indiferencia, es una preferencia proyectada sobre la realidad y los bienes, es una cualidad adjetiva, es una estructura; es un criterio de conducta ${ }^{12}$. Creemos nosotros que el valor es un aprecio individual o colectivo de un bien real y objetivo; que el ser de las cosas es su fundamento ontológico; que a este fundamento se añade la preferencia individual o colectiva, en la que puede radicarse la faceta subjetiva y relativa del valor. Las cosas son, pero los valores significan la importancia que los hombres las damos. El ser de las cosas es previo a todo juicio, mientras que el valor presupone un proceso cognoscitivo, inmerso en la tonalidad emocional, que la epistemología moderna ha descubierto en el acto cognoscitivo. Los valores tienen tanta mayor consistencia cuanto más radican

12. RAEYMAEKER, Filosofía del ser (Madirid 1956) 302; BASAVE, Filosofía del hombre (México 1963) 164; L. E. BATHS, M. HARMIN, S. B. SIMON, El sentido de los valores y la enseñanza (México 1967) 30-32; A. STERN, Filosofía de los valores. Buenos Aires, 1960; F. FRONDIZI, ¿Qué son los valores? ${ }^{5}$ México, 1972. 
en el ser y el bien, pues en caso contrario quedarian reducidos a pura subjetividad. Sin embargo, el aprecio, el gusto y el deseo son reales, aunque subjetivos.

Es posible que la absolutez y la relatividad, la objetividad y la subjetividad puedan copularse, en el estudio de los valores, porque pueden corresponder a diferentes aspectos. La absolutez y la objetividad derivan del sustrato ontológico, mientras que la relatividad y la subjetividad son proyectados por el hombre que aprecia y prefiere. En consecuencia, la jerarquización axiológica de la mayoria de las culturas no coincide con la escala de los seres-bienes.

Tres son los posibles enfoques sobre el valor. El enfoque filosófico y metafísico se mueve en el plano conceptual y responde a la necesidad que el hombre siente acerca de la naturaleza de las cosas; en este plano hay que situar la discusión entablada sobre la relación seres-bienes-fines-valores, sobre sus presupuestos gnoseológicos y sobre el ser del hombre, en cuanto portador de valores. No es competencia de los sistemas educativos dilucidar este aspecto filosófico del valor, aunque lo suponen; sería tema a incluir en una ontología de la educación.

El enfoque psicológico es el específico de la psicología social, que involucra a los valores, las motivaciones, las actitudes y las vivencias en el capítulo sobre socialización. Este enfoque psicológico es muy útil para los valores educativos y para la tarea perfectiva del hombre.

El enfoque sociológico brota de la dimensión cultural del valor, que se torna entonces criterio, pauta de conducta, control social...; los valores, en su dimensión sociológico, dicen referencia al progreso y al cambio social, sobre todo si se piensa en la aceleración histórica, en la revolución cultural y en las mutaciones ideológicas de los grupos humanos. Esta faceta del valor tiene también conexión con el proceso educativo, que es un proceso social.

Filosóficamente es peligroso inclinarse por la relatividad de los valores, ya que incurririamos en relativismos ontológicos para nosotros inválidos. En este sentido, el valor no puede ignorar la absolutez del ser y del bien; pero es indudable que existen cambios en los valores. Las crisis de los valores se plantean en el terreno psicosocial, porque el aprecio individual o colectivo varía y cambia. Las crisis de los valores son el resultado de crisis individuales y sociales. Lo que resulta realmente dificil es probar que las crisis de los valores explican los cambios sociales, por más que resulta arriesgado pronunciarse por la prioridad cronológica de estos fenómenos frecuentes en las comunidades y las culturas. 
Los valores educativos están condicionados por los valores culturales y por la axiología general. La cultura y la naturaleza de los valores nos persuaden de la mutabilidad de los valores educativos, aunque seamos partidarios de la permanencia de los bienes educativos. La polifacética hominidad es la base de la variabilidad diacrónica y espacial. La dialéctica histórica nos induce a defender la mutabilidad de los valores educativos, en sus aspectos psicológicos y sociales. Sería ingenuo prescindir de los hondos problemas ontológicos que avalan esta mutabilidad, desde la época de Parménides y Heráclito.

La sustantividad misma del valor explica esta mutabilidad, ya que en todas las axiologías se insiste en la subjetividad: agrado, preferencia, deseo, aprecio... Nos encontramos, en verdad, ante un componente cognoscitivo emocional, que hace comprensible su mutabilidad. Las cosas son en sí; los valores lo son para alguien o para una sociedad. El oro, por ejemplo, no sufre químicamente inflaciones; pero sí en su aprecio, en cuanto instrumento de transacción, por lo cual se convierte en un valor económico. Poseer una buena memoria, por más que se diga, es siempre un bien, una aptitud positiva natural; pero el aprecio que de ella se haga es variado, según las necesidades ocupacionales y las exigencias de los tiempos. La sumisión puede ser útil en una estructura política totalitarista e ineficaz en otra pluralista y democrática. La mutabilidad de los valores educativos jamás puede provenir del sustrato ontológico, sino de los aspectos psicológico y sociológico.

El carácter epistemológico del valor se patentiza en la conciencia del valor, en el juicio de valor y en la vivencia del valor. La conciencia del valor es la percepción y el reconocimiento de los bienes culturales; el juicio de valor es una operación selectiva subjetivamente condicionada, que no coincide exactamente con los bienes apreciados ${ }^{13}$; la vivencia del valor es la entrega personal al gozo de un determinado sector de los valores. En tanto la teoría del conocimiento no explique satisfactoriamente la esencia del proceso cognoscitivo y de las aptitudes que en él intervienen, continuará enigmática y misteriosa la naturaleza del valor educativo. La frialdad e inoperancia de los esquemas kantianos sobre la invención de la verdad suscitaron soluciones irracionales y vitalistas, que exigian elementos emocionales en el acto cognoscitivo ${ }^{14}$. Si esto es cierto, es

13. Th. MƯNCKER, Die philosophische Grundlegund der katholischen Sittenlehre. Düsseldorf, 1953.

14. S. RABADE, Estructura del conocer humano. Madrid, 1967. 
poco congruente sostener la inmutabilidad de los valores, en su dimensión psicológica y sociológica. Cuando la epistemología haya resuelto estas dificultades, las ciencias de la educación dispondrán de una base fiable en la teoria y en la práctica.

En lo que no podemos incurrir es en un relativismo ético, tal y como se ha dado en el $\mathrm{s}$. $\mathrm{XX}$, por más que deseemos sean revisados los modelos éticos más comunes en occidente. Habrá que salvar la materialidad de las éticas y rechazar la formalidad huera. Pero no es necesario llegar a la concepción biosocial de la ética, al modo de $J$. Dewey o a teorias similares, para negar la validez universal de los sistemas educativos. La ética y la educación guardan tal relación, que es trabajoso encontrar sistemas educativos ajenos al carácter moralizador de la educación. Nuestro más rotundo no al relativismo ético; pero nuestra razonable aceptación del cambio psicológico y social de los valores culturales y educativos.

Favorece también la mutabilidad de los valores educativos la mentalidad evolucionista del saber actual. Tanto si se considera a la educación receptora del cambio axiológico, como si se la estima propulsora de la movilidad cultural, se opera siempre con una mentalidad evolucionista. La concepción superorgánica de $E$. Durkheim sobre el fenómeno social, educativo, la teoría evolucionista naturalista de $H$. Spencer, el indiscriminado uso de la educación para promocionar a los pueblos o para controlarlos social-democráticamente coinciden en esta manera evolucionista de juzgar el proceso educativo ${ }^{15}$.

2.4. Fundamentación histórica. La evolución de la educación institucionalizada nos afianza en la defensa de la no validez universal de los sistemas educativos, si reseñamos las reiteradas crisis en la institución escolar y en su organización, crisis que relegan al olvido métodos y enfoques otrora en olor de aceptación mayoritaria. Cada vez que la sociedad, la cultura y los valores entran en crisis, alcanzan también estos conflictos a la institución escolar, que es, en definitiva, un espejo de la estructura social del momento.

Los teólogos del planeamiento educativo y de la visión futurista de la escuela están persuadidos de que la educación es un factor desencadenante del cambio social y del desarrollo económico. Pero la verdad histórica atestigua que, al menos hasta ahora, estas aspiraciones, sociológicamente justificadas, no se han verificado, pues la educación ha ido a la zaga de los cambios sociales; y no vicever1972.

15. B. SUCHODOLSKI, Fundamentos de Pedagogía socialista. Barcelona, 
sa. Los proyectos prospectivos son un desafío a la institución escolar, a la política educativa y al "rol" que el educador ha de desempeñar en nuestro mundo ${ }^{16}$.

Las crisis educativas son consecuencia del cambio en el concepto de hombre, expreso en el reconocimiento universal de los derechos humanos, en las doctrinas del espiritualismo católico del Concilio Vaticano II, en el pluralismo ideológico y político imperante, en la prospectiva intencionada del ser humano a través de manipulaciones neurológicas, en la creciente socialización, en la repulsa unánime del uso de la violencia en las relaciones sociales, en la aspiración general de aumentar los intervalos de ocio y tiempo libre que liberen al hombre encadenado de la era industrial, en los horizontes ecológicos y antropológicos de los viajes interespaciales y en la convicción común de que la institución escolar es fútil, si vuelve la espalda a la vida y a la existencia.

Las crisis educativas son consecuencia del Selbst-werden (autorrealizarse) de la naturaleza humana y del proceso educativo, intimamente conjugado con la realización del hombre en la libertad, en terminología jasperiana ${ }^{17}$. Si el hombre es un ser en perpetuo fieri, si la sociedad acelera vertiginosamente su caminar, no puede la escuela afincarse en viejas fórmulas, supuestamente válidas, pero inoperantes aquí y ahora.

Si la pedagogía no puede alcanzar una validez universal, nada debe hacernos extraños a las crisis educativas ${ }^{18}$. Si los valores fueran fijos, universales, objetivos y absolutos, apenas si podría variar la educación en su discurso histórico; si, por el contrario, los valores son inestables, subjetivos, parciales y relativos, la educación ha de ser distinta en una cuiltura y en otra. Las crisis educativas han existido, porque no se ha podido encontrar un tipo de escuela válido siempre y para todos los lugares. La más óptima de las escuelas, en un punto geográfico concreto y en un determinado momento hístórico, ha resultado caduca e insuficiente, si se varian el tiempo y el espacio.

Hasta el s. XVIII la Pedagogía fue considerada unitaria y universalmente válida, porque la fundamentación filosófica anterior a la Ilustración así lo postulaba; pervivió la idea de una pedagogia de

16. E. J. KING, Las necesidades de la sociedad moderna y la función del maestro: Buenos Aires, 1973. 540 .

17. K. JASPERS, Psicología de las concepciones del mundo (Madrid 1967)

18. G. DILTHEY, Fundamentos, 120 . 
validez universal en los sistemas perennialistas, muy aceptados en la cultura occidental cristiana, gracias al puente medieval por el que se comunicó el pensamiento grecorromano a las naciones europeas. La indiscriminación de las diversas clases de saberes, anterior al renacimiento, favoreció la concepción absolutista de la educación y de su validez universal. Hasta que los saberes se han diferenciado, era imposible deslindar aspectos diferentes en la concepción absolutista de la educación, por lo que se tropezaba con un "handicap", consistente en el temor a que las mismas concepciones teológicas sufrieran menoscabo en las tesis de la mutabilidad de los sistemas educativos y de los valores. Es precisa una desmitificación del problema, en el terreno estrictamente científico y filosófico, para que no se atribuya categoría teológica al confusionismo y al prejuicio.

La desmitificación no llegó a Norteamérica en las décadas, recientes aún, en las que los progresistas y perennialistas protagonizaron acres luchas, o en las que los relativistas y absolutistas del viejo continente se dedicaron a contradecirse y zancadillearse.

G. Dilthey, pionero de la defensa de la invalidez universal de los sistemas educativos, expresa bellamente este pensamiento:

"Nunca ha visto Europa una enseñanza tan unitaria y con ello tan poderosa, como esta medieval... La unidad tenía que deshacerse. La época de la liberación comenzó. Los grandes movimientos victoriosos en ella son el Renacimiento y la Reforma. Entonces quedó disuelto el sistema teológico-metafísico. En formas elementales esperaba lo nuevo" ${ }^{19}$.

Las crisis educativas aparecen junto con las convulsiones de las instituciones sociales, educadoras también algunas de ellas: iglesia, estado y familia. $\mathrm{Y}$ todas las intituciones, en su historia, han evolucionado.

En las tres últimas centurias observamos correlaciones entre crisis educativas y crisis axiológicas. En el s. XVIII, tras el opacamiento aristotélico, advino el racionalismo y la implantación de las corrientes ilustradas. Fue entonces cuando se puso en tela de juicio la existencia de una pedagogía de validez universal. Rousseau lanzó la doctrina naturalista, que sonó a herejía vitanda en el parlamento, en los medios eclesiásticos y en las instituciones gubernamentales. En el s. XIX, el totalitarismo imperial napoleónico y los

19. G. DILTHEY, Fundamentos, 14. 
nacionalismos purulentos del romanticismo crearon el clima idóneo para la novedosa oferta de la escuela pública, única y laica. En el s. XX, la contestación a las instituciones, incluidas las sagradas, ha extendido su radio de acción a la institución escolar, cuya existencia peligra, y ofrece alternativas ilusorias e ingenuas. En los años de explosión escolar y democratización de la enseñanza, secundadas por socialismos de uno u otro signo, la escuela, sobre todo la superior, ha dejado de ser reducto de distinguidos y de élites, para admitir a nueva savia, extraída de capas sociales modestas, que ansiaban el título universitario, para escalar a sectores sociales más elevados y asegurar un medio de subsistencia, en lugar de continuar sometidas a la esclavitud del analfabetismo, que traía consigo otra esclavitud a los poderosos del dinero y del saber.

\section{Pactano Fermoso Estébanez Universidad Autónoma BARCELONA}

